\title{
Primary care is not the answer
}

\author{
The idea that the United States can solve major problems in medical care by mandating that in the future 50 per cent \\ of physicians go into primary care is wishful thinking.
}

President Bill Clinton's heroic hope of winning a place in history as the visionary who made good medicine instantly available to every man, woman, and child in the United States (while reducing the deficit at the same time) is likely to be dashed by a contrary Congress that is consumed by disagreement on health legislation. That is a good thing, not because Clinton's vision is wrong but because many of the details in his health-care bill are so poorly thought out as to be dangerous. (It should also be said clearly that the real impetus to reforming the health insurance system in the United States is cost, not humanitarianism.)

The big arguments in Congress are about whether all employers (including small businesses) should be required to pay insurance premiums and whether new coverage can be extended to the whole of the population right away.

But less visible provisions in the various versions of health legislation are (or ought to be) equally contentious. One is a provision to force 50 per cent of physicians into what is called 'primary care', known once upon a time as general practice. During the past two decades, the United States has alternately concluded that it had too few physicians, too many, and now, that it has a surplus not of physicians generally but of specialists in particular. From start to finish, the data have been weak but have nonetheless served as the impetus to legislative remedy. So today the fashion is to talk about an oversupply of specialists and the need to create by 2000 (or so) what is facetiously called 'the 50 per cent solution'.

The premise is quite simple. An analysis of the physician population shows a predominance of relatively expensive specialists (cardiologists, gastroenterologists and oncologists, for instance) in cities and suburban areas, and a deficiency of primarycare doctors to provide vaccinations and be there to catch minor illness before it becomes serious disease.

C. Everett Koop, the former US surgeon general known for his outspoken pronouncements during the Reagan administration, recently argued the case to the general public through an article in the 3 July issue of Parade, a tabloid supplement published in nearly every Sunday paper in the country. Koop noted that "in Britain, $72 \%$ of physicians are primary-care doctors. Canada has $54 \%$. Germany and France have $47 \%$ and $48 \%$. We have $29 \%$ and the number is falling." Ergo, the United States needs more primary-care doctors too. Speaking eloquently of the virtues of primary care, Koop aimed at the heart: "The patient is more than the aches and pains he or she brings to you. You may come in to see the doctor about a pain in your elbow, but you may have problems that are economical, emotional, psychological or spiritual." The elbow, Koop argues, is the opening for the primary-care doctor (cum financial adviser, psychiatrist and cleric) to solve problems of all sorts. In Koop's ideal world the patient will go home saying "II don't have a problem with my elbow any more.' Why? Because the doctor has changed his attitudes about life."

This is patent nonsense and dangerous besides. It perpetuates (in fact, reincarnates) the myth of physician as God, and ignores the possibility that the problem with the patient's elbow is rheumatic or orthopaedic in origin and has nothing to do with his or her bank account or soul. It fosters the myth that real people with nice, friendly general practitioners do not get really sick. That makes modern medicine the enemy.

An equally interesting new account of medicine in Britain makes the countervailing argument, although the information has not yet been part of the US debate. According to recent data, people in Britain are more likely to die of cancer (particularly lung, rectal, prostate, stomach and breast cancer) than their counterparts in the United States and Europe. Why? If Kenneth Calman, director of the UK Department of Health, is right, Britain has too few oncologists. Only six out of every 10 women diagnosed with breast cancer in Britain will be alive five years later. In the United States, eight of those same 10 women will survive in relatively good health for more than five years.

There are two important points here. First, the debate about primary-care physicians versus specialists is far more complex that has been portrayed. No one can argue persuasively that modern science has not led to new and useful therapies that are beyond the skill of the generalist, any more than one can argue that all doctors should be highly technically skilled specialists. Furthermore, in the United States at least, there are no data (or provisions in legislation) that will demonstrably solve the problem of physician distribution in poor and rural areas simply by mandating that more medical students should go into primary care.

Second, and even more important, the US education system has, for a quarter of a century or more, been geared to producing specialists - especially at the major academic medical centres in the United States. It is these people (and this system broadly defined) that are the core of the research enterprise that has done so well in advancing not only the care of patients with complex illnesses but also understanding of basic biological phenomena that will produce the next wave of medical progress.

It may be wise to change the system, and the numbers and kinds of physicians who are educated. But not for the reasons put forward so far. The point that health-care reform is really about money, not about high-quality medical care, is worth reiterating because it has become, in part, the basis for the arguments about how many physicians are needed in this or that speciality. The fact that the United States has more specialists than other countries is not, per se, an argument for fewer specialists. Nor is the argument, frequently cited in the medical literature, that managed care systems such as Health Maintenance Organizations (HMOs) employ more generalists than specialists a sensible one on which to base legislative decisions. That argument assumes that HMOs do an equally good job of caring for or referring patients with complex disease - an assumption that has yet to be proved.

A couple of facts need to be faced. First, modern medicine - born of research saves lives but does not always save money, if for no other reason than that the patient cured of one disease will live to get another. Second, it is not always true that medicine in other countries equals that in the United States. Rather, people elsewhere seem to accept levels of care and limits to access that Americans (at least for now) will not. It is said that Americans believe that death is an option. Hyperbole aside, they certainly believe that premature death - death that can be stayed by the hand of medicine to give an individual a longer and reasonably good life - should not be an option. (We are not talking here about the heartlessness of putting the terminally ill on respirators so that they can live out their last days in personal anguish at high cost to society.)

But for appropriate life-prolonging care, specialists and modern biomedical research are essential and should not be ignored in the headlong rush to pass legislation that, in the end, may damage science and, therefore, medicine.

Barbara J. Culliton 